\title{
Oral Health Education for Medical Students: Malaysian and Australian Students' Perceptions of Educational Experience and Needs
}

\author{
Mas S. Ahmad, PhD; Menaka A. Abuzar, PhD; Ishak A. Razak, PhD; \\ Sabariah A. Rahman, MPath; Gelsomina L. Borromeo, PhD
}

Abstract: Education in oral health is important to prepare future medical professionals for collaborative roles in maintaining patients' oral health, an important component of general health and well-being. The aims of this study were to determine the perceptions of medical students in Malaysia and Australia of the quality of their training in oral health care and their perceptions of their professional role in maintaining the oral health of their patients. A survey was administered in the classroom with final-year Malaysian $(n=527$; response rate $=79.3 \%)$ and Australian $(n=455$; response rate: $60 \%)$ medical students at selected institutions in those countries. In the results, most of these medical students reported encountering patients with oral health conditions including ulcers, halitosis, and edentulism. A majority in both countries reported believing they should advise patients to obtain regular dental check-ups and eat a healthy diet, although they reported feeling less than comfortable in managing emergency dental cases. A high percentage reported they received a good education in smoking cessation but not in managing dental trauma, detecting cancerous lesions, or providing dietary advice in oral disease prevention. They expressed support for inclusion of oral health education in medical curricula. These students' experience with and perceptions of oral health care provide valuable information for medical curriculum development in these two countries as well as increasing understanding of this aspect of interprofessional education and practice now in development around the world.

Dr. Ahmad is with the Melbourne Dental School, University of Melbourne, Australia and the Faculty of Dentistry, University Teknologi MARA, Selangor, Malaysia; Dr. Abuzar is Associate Professor, Dental School, University of Melbourne, Australia; Dr. Razak is Professor, Faculty of Dentistry, University Malaya, Kuala Lumpur, Malaysia; Sabariah Rahman is Professor, Faculty of Medicine, University Teknologi MARA, Selangor, Malaysia; and Dr. Borromeo is Convenor, Special Needs Dentistry, Melbourne Dental School, University of Melbourne, Australia. Direct correspondence to Dr. Mas S. Ahmad, Melbourne Dental School, University of Melbourne, 720 Swanston Street, Carlton, Victoria 3053, Australia; +61393411489; mas_suryalis@yahoo.com.

Keywords: medical students, medical education, interprofessional education, oral health education, curriculum development

Submitted for publication 8/25/16; accepted 3/27/17

doi: $10.21815 / J D E .017 .060$

$\mathrm{T}$ he association between oral and systemic health underlines the importance of oral health maintenance in achieving general well-being and a satisfactory quality of life. ${ }^{1,2}$ Since health care professionals strive to promote comprehensive patient care, oral health maintenance should be an essential component of a patient's overall health management plan. Effective management of a patient's oral health requires interprofessional collaboration among health team members, each of whom can play a role in promoting oral health within their scope of practice.

The concept of collaborative oral health management and education has gained recognition as a result of interprofessional programs in community, education, and health care settings around the world. ${ }^{3,4}$ In some countries, such as the United States, United Kingdom, and Poland, oral health education has been introduced into medical curricula, thus providing future physicians with educational experience that emphasizes a holistic care approach. ${ }^{5-9}$ Although medical schools in some parts of the world include training in oral health, the extent of such developments in institutions in the Asia-Pacific region is unknown. The aims of this study were to determine the perceptions of medical students in Malaysia and Australia about the quality of their training in oral health care and their perceptions of their professional role in maintaining the oral health of their patients.

\section{Materials and Methods}

Ethical approval for the study was granted by the University of Melbourne Human Research Ethics Committee (HREC ID: 1136596) and the Research Ethics Committee at the Universiti Teknologi MARA 
(Ref. No: 600-RMI 5/1/6). A paper survey was distributed in classrooms to final-year medical students at selected Malaysian and Australian institutions who were in their final phase of medical study. The instrument was adapted from surveys used in previous studies. ${ }^{10-14}$

Prior to conducting the survey, we tested the instrument in a content-validation process with a panel of senior medical faculty members in both countries, followed by a pilot study with small groups of Malaysian fourth-year $(\mathrm{n}=10)$ and Australian thirdyear $(\mathrm{n}=6)$ medical students. Appropriate modifications were made to the instrument after the content validation and pilot study. The instrument consisted of five sections: sociodemographic characteristics; perceptions of oral health education; training in oral health; awareness of special needs dentistry; and perceptions of interprofessional education (IPE). A plain language statement outlining the objectives of the study, together with information regarding consent and confidentiality, was attached to the survey.

This study was targeted at final-year medical students in both countries in order to gain an overview of their learning experience. At this stage, the students have completed most of their medical program requirements. Four Malaysian medical schools were selected and asked for access to their students based on our plan to include one of each of four types of schools: an established medical school with a co-existing dental school; an established medical school without a co-existing dental school; a less well-established medical school with a co-existing dental school; and a less well-established medical school without a co-existing dental school. Malaysian medical schools with programs conducted for more than 15 years were defined as established. All three medical schools in Victoria, Australia, were approached to ask for access to their students.

Quantitative data were analyzed with chisquare test using Statistical Package for Social Science software, version 22.0 (SPSS Inc., Chicago, IL, USA). Significance was set at $p \leq 0.01$.

\section{Results}

With the exception of one Australian institution, all medical schools in both countries that were approached agreed to allow the study to be conducted with their final-year medical students. The response rate was $79.3 \%(n=527)$ and $60.0 \%(n=455)$ for students attending the four Malaysian and two

\begin{tabular}{|c|c|}
\hline Category & Percentage of Total \\
\hline \multicolumn{2}{|l|}{ By country } \\
\hline Malaysia $(n=527)$ & $53.7 \%$ \\
\hline Australia $(n=455)$ & $46.3 \%$ \\
\hline \multicolumn{2}{|c|}{$\begin{array}{l}\text { Attending a medical school with a dental } \\
\text { school on campus (OVERALL) }\end{array}$} \\
\hline Yes $(n=522)$ & $53.2 \%$ \\
\hline No $(n=460)$ & $46.8 \%$ \\
\hline \multicolumn{2}{|c|}{$\begin{array}{l}\text { Attending a medical school with a dental } \\
\text { school on campus (BY COUNTRY) }\end{array}$} \\
\hline \multirow[t]{2}{*}{ Malaysia } & $68.7 \%$ \\
\hline & $31.3 \%$ \\
\hline Australia & $35.2 \%$ \\
\hline No $(n=295)$ & $64.8 \%$ \\
\hline
\end{tabular}

Australian medical schools, respectively. Table 1 shows the breakdown of participants by country and educational setting.

Very high percentages of participating students in Malaysia and Australia (94.5\% and 93.2\%, respectively) reported having encountered patients presenting with a variety of oral health conditions during their medical training (Figure 1). The most reported oral complications reported being seen by Malaysian vs. Australian students were oral ulcers $\left(67.7 \%\right.$ vs. $\left.75.7 \% ; \chi^{2}=7.788, p=0.005\right)$, halitosis (71.2 vs. $65.7 \%)$, and edentulism (65.7\% vs. $65.3 \%)$. In comparison with their Malaysian counterparts, a significantly higher percentage of Australian students had encountered cases of oral/dental trauma $\left(49.0 \%\right.$ vs. $\left.29.4 \% ; \chi^{2}=39.617, \mathrm{p} \leq 0.01\right)$ and tooth abscess $\left(36.0 \%\right.$ vs. $\left.12.0 \% ; \chi^{2}=79.729, p \leq 0.01\right)$. By comparison, significantly more of the medical students in Malaysia reported encountering children with caries $\left(48.2 \%\right.$ vs. $\left.20.9 \% ; \chi^{2}=79.544, p \leq 0.01\right)$ and patients with toothaches $(38.0 \%$ vs. $30.1 \%$; $\chi^{2}=6.660, p=0.01$ ).

At the country level, a significantly higher percentage of the medical students in Malaysia who attended institutions without a co-existing dental school reported having encountered patients with edentulism $\left(75.2 \%\right.$ vs. $\left.60.8 \% ; \chi^{2}=10.337, \mathrm{p} \leq 0.01\right)$, as well as tooth decay in adults $(73.3 \%$ vs. $47.5 \%$; $\left.\chi^{2}=30.607, \mathrm{p} \leq 0.01\right)$ and children $(63.0 \%$ vs. $41.4 \%$; $\left.\chi^{2}=21.167, \mathrm{p} \leq 0.01\right)$, in comparison with their counterparts at universities with a dental school. A similar scenario was seen in Australia, where a higher percentage of the medical students from 


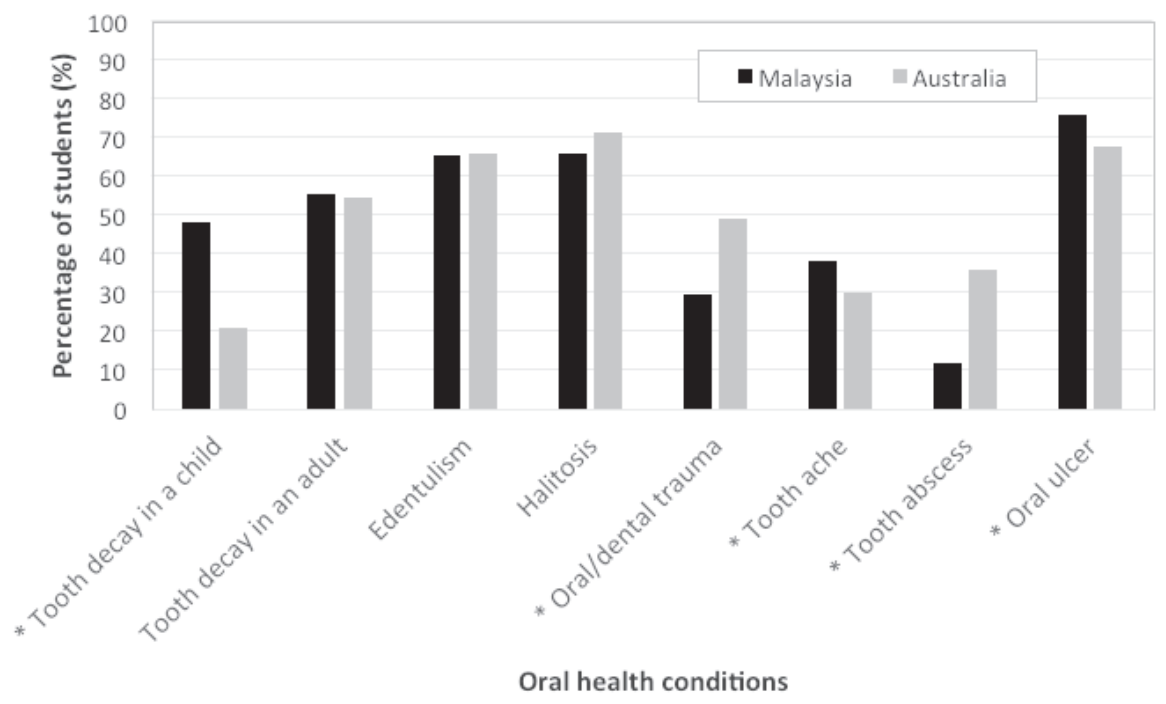

Figure 1. Percentages of participating medical students who reported encounters with patients with specified oral health problems (students in Malaysia $n=527$; students in Australia $n=455$ )

*Statistically significant difference between the two countries at $p \leq 0.01$

institutions without a co-existing dental school, in comparison with those from institutions with a dental school, reported having encountered patients with oral conditions, such as halitosis $(77.6 \%$ vs. $59.4 \%$; $\left.\chi^{2}=16.856, p \leq 0.01\right)$, oral ulcer $(73.2 \%$ vs. $57.5 \%$; $\left.\chi^{2}=11.722, \mathrm{p} \leq 0.01\right)$, edentulism $(69.8 \%$ vs. $58.1 \%$; $\left.\chi^{2}=6.309, \mathrm{p} \leq 0.01\right)$, oral $/$ dental trauma $(55.3 \%$ vs. $\left.37.5 \% ; \chi^{2}=13.085, \mathrm{p} \leq 0.01\right)$, and toothache $(34.9 \%$ vs. $\left.21.3 \% ; \chi^{2}=9.205, \mathrm{p} \leq 0.01\right)$.

Significantly more of the participating medical students in Malaysia reported feeling comfortable with performing oral examinations $(59.2 \%$ vs. $\left.33.4 \% ; \chi^{2}=85.358, \mathrm{p} \leq 0.01\right)$, oral hygiene instruction $\left(56.0 \%\right.$ vs. $\left.45.4 \% ; \chi^{2}=12.284, p=0.002\right)$, dental referrals $\left(52.0 \%\right.$ vs. $\left.46.2 \% ; \chi^{2}=18.632, \mathrm{p} \leq 0.01\right)$, and initial dental emergency treatment (10.0\% vs. $4.6 \%$; $\left.\chi^{2}=162.551, \mathrm{p} \leq 0.01\right)$ in comparison with their Australian counterparts. When we compared students at the country level and for both countries, there was no significant difference between respondents from institutions with a co-existing dental school and those without one in reporting comfort in performing the various oral health activities.

More than three-quarters of all respondents, regardless of country or presence of dental school within the university, reported believing that medical practitioners should advise patients to obtain regular dental check-ups $(83.1 \%$ of Australian and $78.2 \%$ of Malaysian participants; $76.9 \%$ with a co-existing dental school vs. $84.6 \%$ without). When compared with the Australian medical students, a significantly higher percentage of the medical students in Malaysia stated that they believed in the role of medical doctors in educating patients about the effects of dietary habits on oral health $\left(80.4 \%\right.$ vs. $56.5 \% ; \chi^{2}=80.955$, $\mathrm{p} \leq 0.01$ ), performing oral screening as part of routine care $\left(72.5 \%\right.$ vs. $\left.49.7 \% ; \chi^{2}=75.233, p \leq 0.01\right)$, and undergoing training to apply fluoride varnish on dentition $\left(28.5 \%\right.$ vs. $\left.17.0 \% ; \chi^{2}=151.623, \mathrm{p} \leq 0.01\right)$. The Malaysian medical students also reported that they had a more significant role than did the Australian students in educating patients about daily oral hygiene $\left(57.5 \%\right.$ vs. $\left.28.1 \% ; \chi^{2}=140.983, p \leq 0.01\right)$.

In the two countries combined, a significantly higher percentage of the medical students with a dental school on campus (46.4\%), compared to those without $(41.0 \%)$, reported believing in their role in advising for routine oral hygiene maintenance $\left(\chi^{2}=14.570, p=0.001\right)$. At the country level, significantly more Malaysian medical students from institutions without a dental school on campus reported believing that they should advise patients to obtain 
regular dental check-ups with dentists $(87.1 \%$ vs. $\left.74.2 \% ; \chi^{2}=11.038, p \leq 0.01\right)$. There was no significant difference among the medical students at Australian universities, whether the institution had a dental school or not, in terms of their beliefs about the roles of physicians in oral health care.

Although at a low percentage, significantly more of the Malaysian than the Australian medical students stated that they had received good training in performing basic oral health examinations ( $29.6 \%$ vs. $\left.12.3 \% ; \chi^{2}=143.027, p \leq 0.01\right)$, detecting oral cancerous lesions $\left(24.0 \%\right.$ vs. $13.4 \% ; \chi^{2}=67.815$, $\mathrm{p} \leq 0.01$ ), providing advice about the effects of dietary habits on oral health $\left(20.2 \%\right.$ vs. $16.7 \% ; \chi^{2}=42.383$, $\mathrm{p} \leq 0.01)$, and managing dental trauma $(6.1 \%$ vs. $\left.4.6 \% ; \chi^{2}=12.502, p=0.002\right)$. More of the Australian students $(84.6 \%$ Australian vs. $55.0 \%$ Malaysian; $\left.\chi^{2}=103.038, p \leq 0.01\right)$ reported having received good training in smoking cessation. A good training in smoking cessation education was also reported by students from institutions without a co-existing dental school in both countries $(74.9 \%$ medical students from institutions without a dental school vs. $63.3 \%$ medical students from institutions with a dental school; $\chi^{2}=15.913, \mathrm{p} \leq 0.01$ ).

At the country level, a significantly higher percentage of the Australian medical students from institutions without a co-existing dental school reported that they received good training in performing basic oral health examinations ( $16 \%$ vs. $5.6 \%$; $\left.\chi^{2}=12.485, \mathrm{p}=0.002\right)$ and managing dental trauma $\left(5.8 \%\right.$ vs. $\left.2.5 \% ; \chi^{2}=9.629, p=0.008\right)$ although at low percentages. In contrast, there was no significant difference in Malaysian medical students' perceptions of training they received in various oral health-related areas when we compared those from institutions with and without a co-existing dental school.

A high percentage of the students in both Australia (90.4\%) and Malaysia (69.3\%) were unaware of special needs dentistry as a dental specialty $\left(\chi^{2}=64.494, p \leq 0.01\right)$. At the country level, there was no significant difference in responses between students, whether or not there was a dental school on the same campus of the university they attended.

A high percentage of these Australian and Malaysian medical students $(86.0 \%$ and $83.6 \%$, respectively) agreed that oral health should be taught in medical curricula. For the two countries combined, a significantly higher response supporting oral health education in medical school was seen for students at institutions without a co-existing dental school $\left(90.1 \%\right.$ vs. $\left.80.8 \% ; \chi^{2}=19.392, p \leq 0.01\right)$. At the country level, the higher support for oral health education seen by medical students from institutions without a dental school on campus was observed in both Malaysia $\left(91.5 \%\right.$ vs. $\left.79.9 \% ; \chi^{2}=11.032, \mathrm{p} \leq 0.01\right)$ and Australia $\left(67.0 \%\right.$ vs. $\left.33.0 \% ; \chi^{2}=19.392, p \leq 0.01\right)$.

More than $70 \%$ of these medical students in both countries reported that seven important oral health-related areas should be taught in medical curricula: head and neck anatomy, systemic diseases with oral manifestations, effects of poor oral health on systemic health, oral side effects of medications, oral cancers, benign lesions in the oral cavity, and effects of smoking on oral health (Figure 2). They also reported that learning to perform basic oral examinations on adult and pediatric patients was important for medical students. One of the areas of learning rated highest by the Australian respondents was management of dental emergencies; this area was rated significantly lower by the Malaysian students $\left(84.4 \%\right.$ vs. $\left.66.4 \% ; \chi^{2}=41.827, p \leq 0.01\right)$. Areas perceived as less important by the majority of students in both countries were learning about the effects of fluoride on dentition and receiving hands-on training in oral hygiene procedures.

\section{Discussion}

This study investigated Malaysian and Australian medical students' learning experiences in areas relating to oral health care as well as their perceptions of oral health education and practice. Malaysia is a developing country with an increased awareness of health care promotion and provision of services. ${ }^{15}$ Australia was studied as a comparison because it is considered a benchmark in medical education and practice for countries in the Asia Pacific region. ${ }^{15,16}$

This study found that high percentages of medical students in both countries reported encountering patients with oral health conditions. Presentation of oral diseases in medical settings is not uncommon, especially in these two countries where high prevalence of oral diseases has been reported in national oral health surveys. ${ }^{17-20}$ Moreover, a shortage of dentists, especially in rural regions where oral diseases have been found to be higher, requires an increasing role for physicians in managing oral complications in patients. ${ }^{21-26}$

The experience of encountering patients with oral conditions found in our study, especially among students at institutions without a co-existing dental school, indicates an expansion of the oral disease 


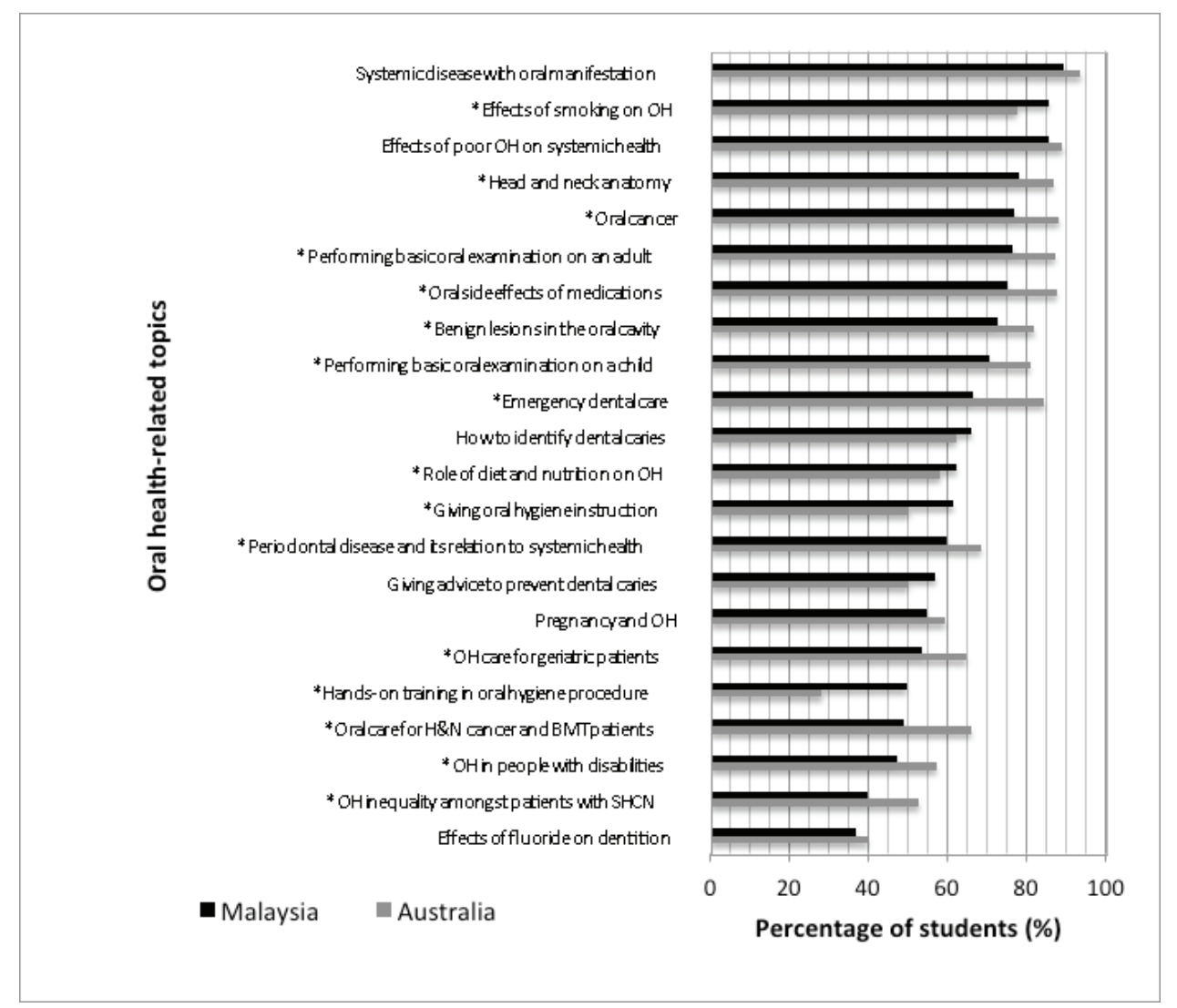

Figure 2. Oral health-related topics perceived by participating students as important to learn during their medical education (Malaysia $n=527$; Australia $n=455$ )

$\mathrm{OH}=$ oral health; $\mathrm{H} \& \mathrm{~N}=$ head and neck; $\mathrm{BMT}=$ bone marrow transplant; $\mathrm{SHCN}=$ special health care needs

*Statistically significant difference between the two countries at $\mathrm{p} \leq 0.01$

burden to medical practitioners for provision of oral health care. These patients may have limited access to dental practitioners, including those in university dental services. In these instances, one of the roles physicians play is identification of oral diseases that require prompt referral, such as oral cancer, since early management leads to better prognosis and increased rate of survival. ${ }^{27,28}$ The presence of acute cases and dental trauma in medical settings found in our study also highlights medical practitioners' role in providing comfort and relief, as well as prevention of life-threatening complications. ${ }^{29}$ In addition, physicians' competence in performing oral examinations may help identify systemic conditions that manifest in the oral cavity, such as diabetes, HIV infection, Crohn's disease, gastroesophageal reflux disorder, and leukemia. ${ }^{30-34}$
The high prevalence of oral health conditions encountered by medical students in both countries in our study also highlights the role of physicians in other areas of preventive care such as smoking cessation, promotion of a healthy and non-cariogenic diet, guidance in oral hygiene practice, and advice for regular dental check-ups. Such preventive care is especially important in patients with special health care needs who are at higher risk of developing oral diseases. ${ }^{35}$ The high utilization of medical services among the increasing number of people with special health care needs in Malaysia and Australia supports the need for physicians to be involved with promotion of daily oral hygiene care. ${ }^{36-39}$ Maintenance of oral hygiene has been found to be an effective preventive measure against systemic conditions such as aspiration pneumonia, infective endocarditis-related bac- 
teremia, Ludwig's angina, mediastinitis, cavernous sinus thrombosis, and cerebrovascular accident. ${ }^{40-45}$

In terms of comfort in undertaking oral healthrelated activities, a significantly higher percentage of the Malaysian medical students than the Australian students in our study reported being comfortable performing oral examinations, delivering oral hygiene instruction, and arranging for dental referrals. The Malaysian students were also more positive about their roles in preventive oral health care. This comfort and beliefs reported by these students may be associated with their educational experience since almost half of Malaysian medical schools provide dedicated teaching hours in oral health. ${ }^{46}$ In spite of this widespread training, only a low percentage of the Malaysian medical students in our study perceived that they had received good training in the various aspects of oral health care. Similarly, a low percentage of the Australian students in our study perceived they had received good training in oral health, although an earlier study found that most Australian medical students received some form of IPE in oral health, but not within dedicated teaching hours. ${ }^{46}$ Perhaps curriculum revision is needed in both countries, along with structured assessment to measure the effectiveness of educational programs in oral health for medical students.

When we compared students' responses according to the presence or absence of a dental school at the same university, we were surprised that those students at institutions without a co-existing dental school were more supportive of oral health education than those at institutions with a dental school. In addition, students on campuses without a dental school were no less comfortable in performing various oral healthrelated activities than their counterparts on campuses with a dental school. Contrary to our assumptions about IPE, having a co-existing dental school had no significant impact on the medical students' performance in or attitudes about oral health education and practice. These students' perceptions of having received good training in various oral health-related areas were also not significantly higher for those at institutions with a co-existing dental school.

Our survey did not ask how the medical students received their oral health education - specifically, whether it was taught by dental school faculty members - so we cannot determine what level of collaboration, if any, existed between medical and dental schools from the same or different campuses in providing this part of the medical curricula. Indeed, medical educators in another study reported a lack of involvement of their dental colleagues in oral health educational activities. ${ }^{46}$ Nevertheless, we would argue that collaboration between medical and dental faculty members has the potential to enhance oral health education programs for medical students. Dental school faculty members can be valuable colleagues and resources for medical faculty members in educating medical students about oral health care as described in a previous study. ${ }^{47}$

Whilst interfaculty collaboration should be encouraged at universities with medical and dental schools on the same campus, support in teaching and learning should also be provided to medical schools that lack inter-institutional access to dental faculty members. The large number of encounters with patients with oral health conditions by students at medical schools without a co-existing dental school found in our study supports the need for at least limited clinical training for medical students in oral health care. To ensure quality training for students without dental faculty members and students on the same campus, teaching and learning collaboration in this area should also be established at the inter-university level. IPE that places medical and dental students together in learning situations can be particularly effective in helping students in both professions learn from each other and prepare them for interprofessional care. ${ }^{48}$

While medical schools endeavor to provide effective training programs for future physicians in collaborative oral health care, guidelines in medical practice and educational requirements also need to be modified to highlight the roles of medical practitioners in oral health maintenance. At present, there is no clear description in the scope of practice defining the role of medical professionals in oral health care for Malaysia and Australia. Accreditation standards of medical curricula, requirements for completion of internship programs, and guidelines on professional duty of care produced by the Malaysian Medical Council, Medical Board of Australia, and other governing bodies in both countries provide only general descriptions of the role of medical professionals in interprofessional practice, with no specific reference to oral health. ${ }^{49-56}$ It may be advisable for Malaysia and Australia to emulate the practice in the United States, where the important role of physicians in collaborative oral health care is shown in the compulsory oral health components of the United States Medical Licensing Examination (USMLE), which is required for licensing of practicing medical professionals in that country. ${ }^{57}$ 
Collaborative efforts in oral health maintenance involving medical practitioners should also include working with specialists in special needs dentistry. These specialists provide oral health management of patients who are medically compromised and/or experiencing some health care conditions that may limit the person's capacity to attain satisfactory oral health.$^{58}$ As physicians manage patients with medical conditions, referral of patients to dentists is sometimes necessary to prevent complications that may result from medical therapy or deterioration of systemic disorders. ${ }^{59}$ Therefore, involvement of special needs dentistry specialists in interprofessional care is important to ensure successful treatment outcome and attainment of overall well-being of patients. It was alarming, however, to see the significantly poor responses among the Australian respondents in our study regarding their awareness of special needs dentistry as a specialty, although this field of dentistry has been recognized in Australia for more than a decade. ${ }^{60}$ Awareness of the roles of such specialists is imperative to ensure appropriate referral and management of these patients when they require dental treatment or consultation. Understanding each other's roles, which is crucial in ensuring effective collaborative care, may be developed through introduction of IPE activities involving these two professions.

In spite of some negative findings, the support for training in oral health expressed by the medical students in this study has positive implications for the future development of education and practice in this area. These students' perceptions of important oral health-related areas can provide administrators or relevant bodies with guidance on topics to be emphasized in designing educational programs in oral health to be incorporated into medical curricula.

Possible limitations of this study include the absence of a sound validation process for the instrument used and the potential for respondent bias previously reported in self-administered surveys. ${ }^{61}$ Furthermore, the use of basic statistical analyses in this study offered limited information, limiting our ability to draw substantive conclusions. However, the information generated by this study does provide useful early findings on the topic, which can support curricular development and guide further in-depth investigation of this subject matter. Future studies should use a survey instrument that has undergone a strong validation process and perform more advanced statistical measurement to provide further useful information.

\section{Conclusion}

This study found that most of the participating medical students in both countries had encountered patients with a variety of oral health conditions. The students reported limitations in their training in oral health care, but they believed they can play a role in oral health provision and promotion. The support for oral health education shown by these students has positive implications for development of training programs to prepare future physicians for roles in collaborative practice in oral health maintenance. Guidelines and requirements that govern the standards of medical education and practice in both countries need to be amended to emphasize the important roles of medical practitioners in collaborative oral health care. These students' experience with and perceptions of oral health care not only provide valuable information for medical curriculum development in these two countries, but also increase understanding of this aspect of interprofessional education and practice in development around the world.

\section{Acknowledgments}

This study was funded by a Melbourne Dental School Postgraduate Research Grant. The authors wish to thank Professor Geoff McColl, Associate Professor Agnes Dodds, and Associate Professor Firdaus Hariri for their valuable contribution to the design and content of the survey, as well as Associate Professor Graham Hepworth, University of Melbourne School of Mathematics and Statistics, for statistical advice. The authors also thank the medical students in Malaysia and Australia who participated in the pilot and main surveys.

\section{Disclosure}

The authors reported no conflicts of interest.

\section{REFERENCES}

1. Liu Z, Zhang W, Zhang J, et al. Oral hygiene, periodontal health, and chronic obstructive pulmonary disease exacerbations. J Clin Periodontol 2012;39(1):45-52.

2. Huang DL, Chan KC, Young BA. Poor oral health and quality of life in older U.S. adults with diabetes mellitus. J Am Geriatr Soc 2013;61(10):1782-8.

3. Victoroff K, Savrin C, Demko C, et al. Interprofessional clinical experiences in dental education. Curr Oral Health Rep 2014;1(3):161-6.

4. Bonwell PB, Parsons PL, Best AM, Hise S. An interprofessional educational approach to oral health care 
in the geriatric population. Gerontol Geriatr Educ 2014;35(2):182-99.

5. Hein C, Schonwetter DJ, Iacopino AM. Inclusion of oralsystemic health in predoctoral/undergraduate curricula of pharmacy, nursing, and medical schools around the world: a preliminary study. J Dent Educ 2011;75(9):1187-99.

6. Ferullo A, Silk H, Savageau JA. Teaching oral health in U.S. medical schools: results of a national survey. Acad Med 2011;86(2):226-30.

7. McCann PJ, Sweeney MP, Gibson J, Bagg J. Training in oral disease, diagnosis, and treatment for medical students and doctors in the United Kingdom. Br J Oral Maxillofac Surg 2005;43(1):61-4.

8. Sandhu A. A survey of oral and maxillofacial surgery teaching in UK medical schools. Br J Oral Maxillofac Surg 2009;47(3):242-3.

9. Loster BW, Likeman PR. Teaching of dentistry to medical students in English at the Jagiellonian University, Krakow, Poland. Eur J Dent Educ 2012;16(1):e1-2.

10. Mouradian WE, Reeves A, Kim S, et al. A new oral health elective for medical students at the University of Washington. Teach Learn Med 2006;18(4):336-42.

11. AlYousefY, Damiano P, Weber-Gasparoni K, et al. Medical students' child oral health-related knowledge, practices, and attitudes. Eur J Dent Educ 2013;17(4):218-24.

12. Rabiei S, Mohebbi SZ, Patja K, Virtanen JI. Physicians' knowledge of and adherence to improving oral health. BMC Public Health 2012;12:855.

13. Ahmad MS, Razak IA, Borromeo GL. Special needs dentistry: perception, attitudes, and educational experience of Malaysian dental students. Eur J Dent Educ 2015;19(1):44-52.

14. Williams B, Lewis B, Boyle M, et al. A survey of undergraduate health science students' views on interprofessional education and the use of educational technology: preliminary analyses and findings. JEPHC 2008;6(4):1.

15. Organization for Economic Cooperation and Development, World Health Organization. Health at a glance, Asia/Pacific, 2014: measuring progress towards universal health coverage. 2014. At: www.oecd.org/health/healthat-a-glance-asia-pacific-23054964.htm. Accessed 24 Aug. 2016.

16. Times (London) Higher Education. World university rankings, subject ranking 2014-15: clinical, preclinical, and health. 2015. At: www.timeshighereducation.co.uk/ world-university-rankings/2015/subject-ranking/clinicalpre-clinical-health-/. Accessed 22 Aug. 2016.

17. Oral Health Division, Ministry of Health Malaysia. National oral health survey of adults, 2010. Putrajaya, Malaysia: Ministry of Health Malaysia, 2013.

18. Australian Institute of Health and Welfare. The national survey of adult oral health, 2004-06. Canberra: Australian Institute of Health and Welfare, 2007.

19. Verma S, Chambers I. Dental emergencies presenting to a general hospital emergency department in Hobart, Australia. Aust Dent J 2014;3:329.

20. Ramli R, Rahman NA, Rahman RA, et al. A retrospective study of oral and maxillofacial injuries in Seremban Hospital, Malaysia. Dent Traumatol 2011;27(2):122-6.

21. Lim G, Rampal S, Yahaya HE. Cancer incidence in peninsular Malaysia, 2003-05. 2008. At: www.moh.gov.my/
images/gallery/Report/Cancer/CancerIncidenceinPeninsularMalaysia2003-2005x1x.pdf. Accessed 24 Aug. 2016.

22. Ariyawardana A, Johnson NW. Trends of lip, oral cavity, and oropharyngeal cancers in Australia, 1982-2008: overall good news but with rising rates in the oropharynx. BMC Cancer 2013;13(1):1-10.

23. Zain RB, Ghazali N. A review of epidemiological studies of oral cancer and precancer in Malaysia. Ann Dent University Malaya 2001;8:50-6.

24. Derbi HA, Kruger E, Tennant M. Incidence of oral cancer in Western Australia (1982-2009): trends and regional variations. Asia Pac J Clin Oncol 2016;12(1):e305-10.

25. Umer A, Umer A. Oral health care in Malaysia: a review. Pakistan Oral Dent J 2011;31(1):141-5.

26. Australian Institute of Health and Welfare. Dental workforce, 2012. National health workforce series no. 7. 2014. At: www.aihw.gov.au/WorkArea/DownloadAsset. aspx?id=60129545958. Accessed 24 Aug. 2016.

27. Ford PJ, Farah CS. Early detection and diagnosis of oral cancer: strategies for improvement. J Cancer Policy 2013;1(1):e2-7.

28. Sciubba JJ. Oral cancer: the importance of early diagnosis and treatment. Am J Clin Dermatol 2001;2(4):239-51.

29. Cohen LA. Expanding the physician's role in addressing the oral health of adults. Am J Public Health 2013;103(3):408-12.

30. de Faria PR, Vargas PA, Saldiva PH, et al. Tongue disease in advanced AIDS. Oral Dis 2005;11(2):72-80.

31. Guan G, Firth N. Oral manifestations as an early clinical sign of acute myeloid leukaemia: a case report. Aust Dent J 2015;60(1):123-7.

32. Ali DA, Brown RS, Rodriguez LO, et al. Dental erosion caused by silent gastroesophageal reflux disease. J Am Dent Assoc 2002;133(6):734-7; quiz 68-9.

33. Stavropoulos F, Katz J, Guelmann M, Bimstein E. Oral ulcerations as a sign of Crohn's disease in a pediatric patient: a case report. Pediatr Dent 2004;26(4):355-8.

34. Preshaw PM, Alba AL, Herrera D, et al. Periodontitis and diabetes: a two-way relationship. Diabetologia 2012;55(1):21-31.

35. Purohit BM, Singh A. Oral health status of 12-year-old children with disabilities and controls in Southern India. WHO South East Asia J Public Health 2012;1(3):330-8.

36. Abdul Rahim FS, Mohamed AM, Marizan Nor M, Saub R. Dental care access among individuals with Down syndrome: a Malaysian scenario. Acta Odontol Scand 2014;72(8):999-1004.

37. Australian Institute of Health and Wefare. Access to health services by Australians with disability, 2012. AIHW bulletin no. 129. 2015. At: www.aihw.gov.au/publicationdetail/?id=60129551404. Accessed 22 Aug. 2016.

38. United Nations Economic and Social Commission for Asia and the Pacific. Disability at a glance 2012: strengthening the evidence in Asia and the Pacific. 2012. At: www.unescapsdd.org/files/documents/PUB_DisabilityGlance-2012.pdf. Accessed 24 Aug. 2016.

39. Australian Bureau of Statistics. Disability, ageing, and carers. 2012. At: www.nesa.com.au/media/64541/140417 abs_4430.0_disability_ageing and carers_australia.pdf. Accessed $2 \overline{4}$ Aug. $201 \overline{6}$. 
40. Yoneyama T, Yoshida M, Ohrui T, et al. Oral care reduces pneumonia in older patients in nursing homes. J Am Geriatr Soc 2002;50(3):430-3.

41. Munro CL, Grap MJ, Elswick RK Jr, et al. Oral health status and development of ventilator-associated pneumonia: a descriptive study. Am J Crit Care 2006;15(5):453-60.

42. Lockhart PB, Brennan MT, Thornhill M, et al. Poor oral hygiene as a risk factor for infective endocarditis-related bacteremia. J Am Dent Assoc 2009;140(10):1238-44.

43. Paterson P, Nichols EH, Watson K, Boyd D. The importance of early intervention in the treatment of dental infection. Dent Update 2014;41(1):68.

44. Verma R, Junewar V, Singh R, et al. Bilateral cavernous sinus thrombosis and facial palsy as complications of dental abscess. Natl J Maxillofac Surg 2013;4(2):252-5.

45. Lafon A, Pereira B, Dufour T, et al. Periodontal disease and stroke: a meta-analysis of cohort studies. Eur J Neurol 2014;21(9):1155-67.

46. Ahmad MS, Abuzar MA, Razak IA, et al. Educating medical students in oral health care: current curriculum and future needs of institutions in Malaysia and Australia. Eur J Dent Educ, forthcoming.

47. Bridges DR, Davidson RA, Odegard PS, et al. Interprofessional collaboration: three best practice models of interprofessional education. Med Educ Online 2011;16(1):1-10.

48. Haber J, Hartnett E, Allen K, et al. The impact of oralsystemic health on advancing interprofessional education outcomes. J Dent Educ 2017;81(2):140-8.

49. Medical School Accreditation Committee. Standards for assessment and accreditation of primary medical programs by the Australian Medical Council. 2012. At: www.amc.org.au/joomla-files/images/Accreditation/ FINAL-Standards-and-Graduate-Outcome-Statements20-December-2012.pdf. Accessed 17 April 2016.

50. Australian Medical Association. Role of the doctor position statement. 2011. At: ama.com.au/system/tdf/documents/Role_of the Doctor_Position_Statement_2011_0. 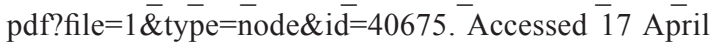 2016.
51. Medical Board of Australia. Good medical practice: a code of conduct for doctors in Australia. 2014. At: www. medicalboard.gov.au/Codes-Guidelines-Policies/Codeof-conduct.aspx. Accessed 17 April 2016.

52. Australian Council for Safety and Quality in Health Care. Standard for credentialing and defining the scope of clinical practice: a national standard for credentialling and defining the scope of clinical practice of medical practitioners for use in public and private hospitals. 2004. At: www.safetyandquality.gov.au/wp-content/ uploads/2012/01/credentl1.pdf. Accessed 17 April 2016.

53. Malaysian Medical Council. A guidebook for house officers. 2008. At: www.mmc.gov.my/v1/images/contents/ ethical/A-Guidebook.pdf. Accessed 17 April 2016.

54. Malaysian Medical Council. Good medical practice. 2001. At: www.mmc.gov.my/v1/images/contents/ethical/GoodMedical-Practice.pdf. Accessed 17 April 2016.

55. Malaysian Medical Council. Code of professional conduct. 1986. At: www.mmc.gov.my/v1/index.php/tester?id=320. Accessed 17 April 2016.

56. Malaysian Medical Council. Credentialing: guideline on competence and practice and to establish monitoring mechanism for highly specialized procedures. 2008. At: www.mmc.gov.my/v1/images/contents/ethical/ CREDENTIALING.pdf. Accessed 17 April 2016.

57. United States Medical Licensing Examination. USMLE content outline. 2015. At: www.usmle.org/pdfs/usmlecontentoutline.pdf. Accessed 17 April 2016.

58. Royal Australasian College of Dental Surgeons. Specialist dental practice. 2015. At: www.racds.org/RACDSNEW_Content/Education/Specialist_Dental_Practice. aspx. Accessed 24 Aug. 2016.

59. Di Fede O, Fusco V, Matranga D, et al. Osteonecrosis of the jaws in patients assuming oral bisphosphonates for osteoporosis: a retrospective multi-hospital-based study of 87 Italian cases. Eur J Internal Med 2013;24:784-90.

60. Shnider WH. Special needs dentistry: the next ten years. Ann R Australas Coll Dent Surg 2008;19:165-8.

61. Bowling A. Mode of questionnaire administration can have serious effects on data quality. J Public Health (Oxf) 2005;27(3):281-91. 